\title{
Combination of lodine-125 brachytherapy and chemotherapy for locally recurrent stage III non-small cell lung cancer after concurrent chemoradiotherapy
}

\author{
Xiaojuan $\mathrm{Yu}^{\dagger}$, Jin $\mathrm{Li}^{\dagger}$, Xiaoming Zhong and Jingdong $\mathrm{He}^{*}$
}

\begin{abstract}
Background: Locally recurrent non-small cell lung cancer (NSCLC) poses a great challenge to physicians. This study aimed to explore the efficacy and safety of the combination of brachytherapy and docetaxel and cisplatin for the treatment of locally recurrent stage III NSCLC.

Methods: Fifty two patients with locally recurrent stage III NSCLC after concurrent chemoradiotherapy were randomly divided into two groups $(n=26)$. The patients in experimental group were treated with implantation of radioactive ${ }^{125}$ I seeds and DP regimen (docetaxel $60 \mathrm{mg} / \mathrm{m}^{2} /$ cisplatin $75 \mathrm{mg} / \mathrm{m}^{2}$ ). Patients in control group received DP chemotherapy. The local control rate (LCR), progression-free survival (PFS), and overall response rate (ORR) were defined according to the Response Evaluation Criteria in Solid Tumors (RECIST).
\end{abstract}

Results: With a median follow-up time of 11 months, PFS and LCR was 8 months (95 \% Cl: 6.99-9.01 months) vs. 5.5 months (95\% Cl: 4.43-6.57 months) $(P<0.05)$ and 10 months (95 \% Cl: 8.72-11.28 months) vs. 6.2 months (95\% Cl: 5.27-7.13 months) $(P<0.05)$ in the experimental and control groups, respectively. The ORR did not differ between treatment groups and was noted to be $69.2 \%$ and $57.7 \%$, respectively $(P>0.05)$. There was no occurrence of severe complications in experimental and control groups.

Conclusion: The combination of ${ }^{125}$ | brachytherapy and second-line chemotherapy is superior to chemotherapy alone and is an effective and safe therapy for this disease.

Trial registration number: ChiCTR-IOR-15006560

Keywords: Brachytherapy, lodine-125, Non-small cell lung cancer, Recurrence

\section{Background}

Lung cancer is the leading cause of malignant tumor death. Non-small cell lung cancer (NSCLC) accounts for $80-85 \%$ of lung cancers. For advanced inoperable NSCLC, combined chemoradiotherapy is considered as the standard first-line treatment [1]. Phase III clinical trials have demonstrated that docetaxel is an effective therapeutic agent for recurrent NSCLC after first-line treatment. Nevertheless, for the patients who are treated

\footnotetext{
*Correspondence: hjddr1@163.com

${ }^{\dagger}$ Equal contributors

Department of Oncology, Huai'an First People's Hospital, Nanjing Medical University, 6 Beijing Road West, Huai'an, Jiangsu 223300, China
}

with docetaxel-based second-line therapy, their overall survival (OS) is usually short and prognosis is poor [2].

Treatment of locally recurrent NSCLC after first-line concurrent chemoradiotherapy poses a great challenge to physicians [3]. Although chemoradiotherapy can be considered as an option for subsequent treatment, its application is strictly limited due to the normal tissue tolerance dose of radiation and the development of severe complications, including chronic basic pulmonary diseases (e.g. chronic obstructive emphysema), radiation pneumonitis, radiation esophagitis, and tracheal necrosis [4].

Currently, implantation of iodine-125 $\left({ }^{125} \mathrm{I}\right)$ seeds is a treatment option for interstitial brachytherapy in lung cancer [5]. The implanted ${ }^{125}$ I seeds can generate a high 
dose (140-160 Gy) within target tumor volumes to continuously destroy tumor cells, while the surrounding non-neoplastic tissues only receive a very low dose and subject to little damage. In addition, the low radiation dose rate can induce the reoxygenation and increased blood flow of hypoxic tumor volumes, thus producing radiation-induced bystander effect to kill tumor cells that can overcome the inhomogeneous distribution of radiation dose [6, 7]. Percutaneous CT-guided ${ }^{125} \mathrm{I}$ seed permanent implantation can decrease the local recurrence in the treatment of high-risk stage I NSCLC with less tissue injury and few complications [8]. ${ }^{125}$ I seed implantation decrease the local recurrence, especially in those with a positive cytology at the staple line [9]. Therefore, we hypothesized that the combination of ${ }^{125} \mathrm{I}$ brachytherapy and second-line chemotherapy may be ideal for the treatment of locally recurrent stage III nonsmall cell lung cancer after first-line therapy. Nevertheless, this combined therapy is uncommonly used and its efficacy and safety remain unclear. In this study we performed a systematic assessment on the clinical efficacy of the combination of brachytherapy with radioactive iodine-125 $\left({ }^{125} \mathrm{I}\right)$ seeds and chemotherapy for the treatment of locally recurrent stage III NSCLC.

\section{Methods}

\section{Patient selection and inclusion}

Inclusion criteria were as follows: patients with locally recurrent stage III NSCLC within one year after receiving concurrent chemoradiotherapy; time of survival was estimated to be longer than three months; tumor diameter was less than $6 \mathrm{~cm}$; no severe liver insufficiency or renal insufficiency, heart diseases, diabetes, coagulation dysfunction, and other chronic diseases; no severer chronic obstructive pulmonary diseases; the Eastern Cooperative Oncology Group (ECOG) score was no more than 2; tumor lesion was suitable for brachytherapy, as the location and size of the lesion were confirmed by chest CT scanning; patients intended to receive the treatments; patients did not receive any radiotherapy and chemotherapy within 3 months of this study. Local recurrence was defined as a $20 \%$ increase in the volume of primary tumor mass from the point of maximum tumor regression in the lung without lymph node metastasis. All patients were evaluated by the investigators of this study (including the oncologists, surgical specialists, and radiologists of Huai'an First People's Hospital Affiliated to Nanjing Medical University) and confirmed to be able to receive the second-line chemotherapy by paclitaxel $\left(135 \mathrm{mg} / \mathrm{m}^{2}\right.$, at day 1) plus cisplatin $\left(75 \mathrm{mg} / \mathrm{m}^{2}\right.$, at day 2) and CT-guided radioactive ${ }^{125}$ I seed implantation.

Based on pathological conformation, 52 patients with locally recurrent lung cancer within 3-12 months after receiving concurrent chemoradiotherapy were included in this study. Prior to the procedure, all patients received multiple imaging examinations including chest $\mathrm{CT}$, abdominal CT or magnatic resonance imaging (MRI), cranial MRI, and bone emission computed tomography (ECT), blood routine examination, blood coagulation tests, hepatic and renal function tests, pulmonary function tests, and electrocardiogram (ECG). Tumor staging was according to American Joint Committee on Cancer (AJCC) staging manual (7th edition). All patients were previously treated by 6 - or $15-\mathrm{MV}$ X-ray beams produced by Siemens ONCOR Expression Linear Accelerator (Siemens AG, Muenchen, Germany). The dose was 2 Gy once daily, 5 times a week, for $6-7$ weeks. The total radiation dose received was 66-70 Gy. The concurrent chemotherapy was paclitaxel $\left(135 \mathrm{mg} / \mathrm{m}^{2}\right.$, at day 1$)$ plus cisplatin $\left(75 \mathrm{mg} / \mathrm{m}^{2}\right.$, at day 2$)$, which was intravenously infused prior to radiotherapy and repeated after four weeks, for four cycles. The median time to recurrence was 7.9 months (range: 5.5-11.2 months). The study protocols were approved by Ethics Committee of Huai'an First People's Hospital Affiliated to Nanjing Medical University and all patients gave signed informed consent.

\section{Study design}

This was a prospective study (Trial registration number ChiCTR-IOR-15006560). The 52 patients were divided into two groups using computer-produced digital random method: experimental group, the patients received the combined therapy of $125 \mathrm{I}$ seed implantation, docetaxel $(60 \mathrm{mg} / \mathrm{m} 2$ at day 1$)$, and cisplatin $(75 \mathrm{mg} / \mathrm{m} 2$ at day 2); control group, the patients received the combination of docetaxel $(60 \mathrm{mg} / \mathrm{m} 2$ at day 1) and cisplatin (75 $\mathrm{mg} / \mathrm{m} 2$ at day 2). Chemotherapy cycle length was three weeks and planned duration of chemotherapy was four cycles. Primary endpoints were progression-free survival and time of local control. CT/PET scans were not available during the years of the study due to economic reasons.

\section{CT-guided implantation of ${ }^{125}$ s seeds}

Sixty-four slice spiral CT scanner (SIEMENS Somatom Sensation 64 CT Scanner) was provided by Siemens. Radiotherapy treatment planning system (TPS) HGGR-2000 was provided by Zhuhai Hokai Medical Instruments Co., Ltd (Zhuhai, China). Implantation needle (18 Gauge), implantation gun, and ${ }^{125}$ I seeds were provided by Ningbo Jun'an Pharmaceutical Technology Co., Ltd (Ningbo, China). The planning target volume (PTV) of lung tumor was defined and outlined after CT scan. Radiotherapy treatment plan for each patient was optimized according to the safety margin around the tumor volume or normal tissues and the radiation dose and radioactivity of ${ }^{125} \mathrm{I}$ seeds. The ${ }^{125} \mathrm{I}$ radioactive seeds used in this study had a length of 
$4.5 \mathrm{~mm}$ and a diameter of $0.8 \mathrm{~mm}$, with an average energy of $27-32 \mathrm{keV}$, a half life of 59.6 days, and a tissue penetration range of $1.7 \mathrm{~cm}$. The initial dose rate was $7 \mathrm{cGy} / \mathrm{h}$ prescribed to $1 \mathrm{~cm}$ depth, and the prescription dose was 90-110 Gy. The ideal position for radioactive seed implantation was determined based on pre-operative TPS and physical condition of patients. The correct entry point, the direction of needle advancement, and the space between implanted ${ }^{125}$ I seeds were determined under CTguidance. After intramuscular injection of $10 \mathrm{mg}$ diazepam and $100 \mathrm{mg}$ pethidine hydrochloride, ${ }^{125}$ I seeds were implanted in the tissues via needles. The space between the implanted seeds was $1.5 \mathrm{~cm}$. The activity of ${ }^{125} \mathrm{I}$ seeds was $2.22-2.59 \times 10^{7} \mathrm{~Bq}$. Post-operative chest CT examination was performed to monitor the implantation-related complications (e.g. pulmonary hemorrhage, pneumothorax, or migration of radioactive seeds). Acquired CT images were then transferred to TPS for the dosimetry evaluation of implanted ${ }^{125}$ I seeds. The evaluation indicators included the tumor matched peripheral dose (MPD) and the dose that $90 \%$ of the target volume received $\left(D_{90}\right)$. Postoperative monitoring of vital signs was conducted for all patients. Antibiotic prophylaxis was used to prevent post-operative infection. One week after the implatation, hemogram was examined to detect any complications.

\section{Evaluation of efficacy and safety}

The efficacy was evaluated three months after interstitial permanent implantation of ${ }^{125} \mathrm{I}$ seeds. Tumor response was evaluated based on imaging findings in accordance with the Response Evaluation Criteria in Solid Tumors (RECIST) criteria: complete response (CR), complete disappearance of target lesions (negative findings or only funicular shadows on imaging evaluation); partial response (PR), at least a $30 \%$ decrease in the sum of the longest diameters of target lesions; progressive disease (PD), at least a $20 \%$ increase in the sum of the longest diameters of target lesions or the appearance of one or more new lesions; stable disease (SD), neither sufficient shrinkage to qualify for $\mathrm{PR}$ nor sufficient increase to qualify for PD. The response rate (RR) of treatment was calculated using the following formula: $R R=(C R+P R) /$ total number of patients $\times 100 \%$. The acute and late radiation toxicities were assessed according to toxicity criteria of the Radiation Therapy Oncology Group (RTOG) and the European Organization for Research and Treatment of Cancer (EORTC) [10].

\section{Follow-up}

All patients were followed up from January 2006 until the time of local recurrence and disease progression. The range of follow-up was 4.5-24 months, with a median of 11 months.

\section{Statistical analysis}

Statistical analysis was performed using SPSS 13.0 software. Kaplan-Meier survival curve method was used to estimate local control rate and PFS. The log-rank test was used to compare the difference between two treatment groups. Fisher's exact test was used to assess the difference in CR rate and short-term efficacy between both groups. $P<0.05$ was considered statistically significant.

\section{Results}

Of 26 patients who received ${ }^{125} \mathrm{I}$ brachytherapy, 15 were male and 11 were female. The median age was 62 years (age range: $48-72$ years). Nine patients had squamous cell carcinoma, 16 had adenocarcinoma, and one had large cell carcinoma. Fourteen patients had stage IIIa NSCLC and 12 had stage IIIb NSCLC (Table 1). The number of implanted ${ }^{125} \mathrm{I}$ seeds in these patients ranged between 15 and 92, with a median number of 34. The immediate post-operative CT scan demonstrated that the tumor MPD in these patients ranged between 90.2 and $130.6 \mathrm{~Gy}$, with a median dose of $110.0 \mathrm{~Gy}$. The $\mathrm{D}_{90}$ was 103.6-148.2 Gy in these patients, with a median dose of 128.9 Gy (Table 2). After brachytherapy, re-implantation of ${ }^{125} \mathrm{I}$ seeds was required in one patient. Three patients had mild pneumothorax, two patients had hemoptysis, two had low-grade fever, and seed migration was observed in one patient. The patients with mild pneumothorax received conservative therapy and finally recovered completely. Another patient with grade III

Table 1 Baseline characteristics of patients enrolled in this study

\begin{tabular}{|c|c|c|c|c|}
\hline \multirow[t]{2}{*}{ Characteristics } & & \multicolumn{2}{|c|}{ Number of cases } & \multirow[t]{2}{*}{$P$ value } \\
\hline & & $\begin{array}{l}\text { Experimental } \\
\text { group }(N=26)\end{array}$ & $\begin{array}{l}\text { Control group } \\
(N=26)\end{array}$ & \\
\hline \multirow[t]{2}{*}{ Gender } & Male & 15 & 17 & \multirow[t]{2}{*}{0.776} \\
\hline & Female & 11 & 9 & \\
\hline \multirow[t]{2}{*}{ Stage } & $\| I I A$ & 14 & 16 & \multirow[t]{2}{*}{0.779} \\
\hline & $\| \mathrm{II}$ & 12 & 10 & \\
\hline \multirow[t]{2}{*}{ ECOG score } & $0-1$ & 22 & 20 & \multirow[t]{2}{*}{0.726} \\
\hline & 2 & 4 & 6 & \\
\hline \multirow[t]{3}{*}{ Pathology } & $\begin{array}{l}\text { Squamous cell } \\
\text { carcinomas }\end{array}$ & 9 & 11 & \multirow[t]{3}{*}{0.656} \\
\hline & Adenocarcinomas & 16 & 13 & \\
\hline & $\begin{array}{l}\text { Large-cell } \\
\text { carcinomas }\end{array}$ & 1 & 2 & \\
\hline \multirow[t]{2}{*}{ Differentiation } & $\begin{array}{l}\text { Well } \\
\text { differentiated }\end{array}$ & 7 & 3 & \multirow[t]{2}{*}{0.291} \\
\hline & $\begin{array}{l}\text { Poorly } \\
\text { differentiated }\end{array}$ & 19 & 23 & \\
\hline \multirow{2}{*}{$\begin{array}{l}\text { Tumor size } \\
\text { (diameter) }\end{array}$} & $3 \mathrm{~cm}$ & 16 & 20 & \multirow[t]{2}{*}{0.368} \\
\hline & $3-6 \mathrm{~cm}$ & 10 & 6 & \\
\hline
\end{tabular}


Table 2 Parameters of brachytherapy with radioactive ${ }^{125}$ I seeds

\begin{tabular}{lll}
\hline Parameters & Median value & Range \\
\hline MPD (Gy) & 110.0 & $90.2-130.6$ \\
D $_{90}(G y)$ & 128.9 & $103.6-148.2$ \\
Number of seeds implanted & 34 & $15-92$ \\
Activity (mCi per seed) & 0.6 & $0.6-0.9$ \\
Dose rate (Gy/h) & 0.07 & $0.05-0.09$ \\
\hline
\end{tabular}

radiation pneumonitis obtained symptom relief after drug therapy (Table 3 ). There were no grade $4 / 5$ complications in both experimental and control groups. The CT scan images of one representative patient were shown in Fig. 1.

For patients who received the combined therapy of ${ }^{125}$ I brachytherapy and DP chemotherapy, the time of local control was between 4.5 and 24 months, with a median of 10 months (95 \% CI: 8.72-11.28 months). Of the patients in this cohort, three achieved progression free of disease after 24-month follow-up. The median PFS was 8 months (95 \% CI: 6.99-9.01 months). The range of PFS was 3-24 months. Three months after ${ }^{125} \mathrm{I}$ brachytherapy, the overall response rate (ORR) was $69.2 \%(18 / 26)$. The rates of CR, PR, SD, and PD in this cohort were $38.5 \%(10 / 26), 30.8 \%(8 / 26), 23.8 \%(6 / 26)$, and $7.7 \%(2 / 26)$, respectively. For the control group, the time of local control was 3-15 months, with a median of 6.2 months (95 \% CI: 5.27-7.13 months). The median PFS was 5.5 months (95 \% CI: 4.43-6.57 months). The range of PFS was 3-10 months. The overall response rate was $57.7 \%(15 / 26)$. The rates of CR, PR, SD, and $\mathrm{PD}$ in this cohort were $7.7 \%(2 / 26), 50.0 \%(13 / 26)$, $30.8 \%(8 / 26)$, and $11.5 \%(3 / 26)$, respectively.

There was no significant difference in ORR between the experimental group and the control group $(\chi 2=0.75$, $P=0.57>0.05)$. For the rate of $C R$, the time of local control, and PFS, there was significant difference between both groups $(\chi 2=7.43, P=0.02<0.05$ for the rate

Table 3 Complications in patients after brachytherapy with radioactive ${ }^{125} \mid$ seeds

\begin{tabular}{lll}
\hline Complications & $\begin{array}{l}\text { Experimental group } \\
(n=26)\end{array}$ & $\begin{array}{l}\text { Control group } \\
(n=26)\end{array}$ \\
\hline Grade 4/5 complications & 0 & 0 \\
Mild complications & & \\
Mild pneumothorax & 3 & 3 \\
Hemoptysi & 2 & 3 \\
Low-grade fever (38.5 C) & 2 & 5 \\
Radiation pneumonitis & 1 & 0 \\
Seed migration & 1 & 0 \\
Local skin erythema & 0 & 1 \\
No complications & 17 & 14 \\
\hline
\end{tabular}

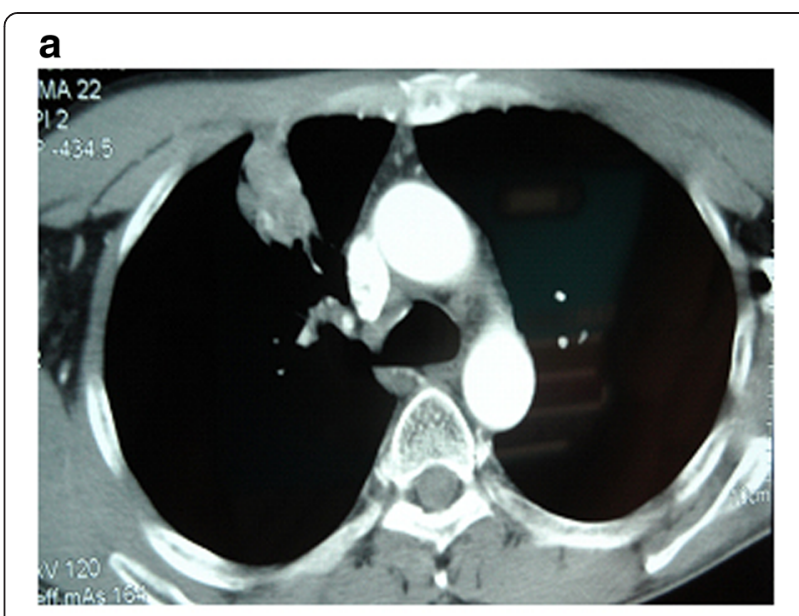

\section{b}

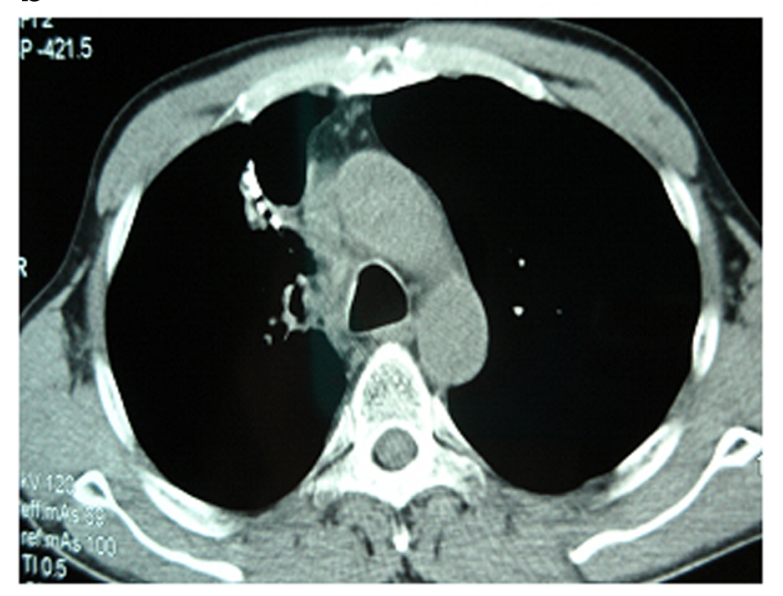

Fig. 1 The reccurent tumot lesions in a representative patient who previsouly received concurrent chemoradiotherapy (a). After the combination of ${ }^{125}$ I brachytherapy and DP regimen, complete disappearance of target lesions was achieved (b)

of CR; $X 2=8.59, P=0.003<0.01$ for the time of local control; $X^{2}=4.7, P=0.04<0.05$ for PFS) (Figs. 2 and 3 ). The median time of local control in the experimental group and the control group was 10 and 6.2 months, respectively. There was significant difference in this outcome between two groups $(P<0.05)$. For PFS, the experimental group had a median of 8.0 months, which was significantly longer than that in the control group (5.5 months) $(P<0.05)$.

\section{Discussion}

Lung cancer is the most common cancer worldwide. The majority of lung cancer patients are not diagnosed until the disease is at the relatively late stage. The patients with advanced lung cancer usually have a very short survival. Currently, lung cancer therapies are not satisfactory in their efficacy of improving the survival of patients. Clinical studies have proven that concurrent chemoradiotherapy is a standard treatment for locally 


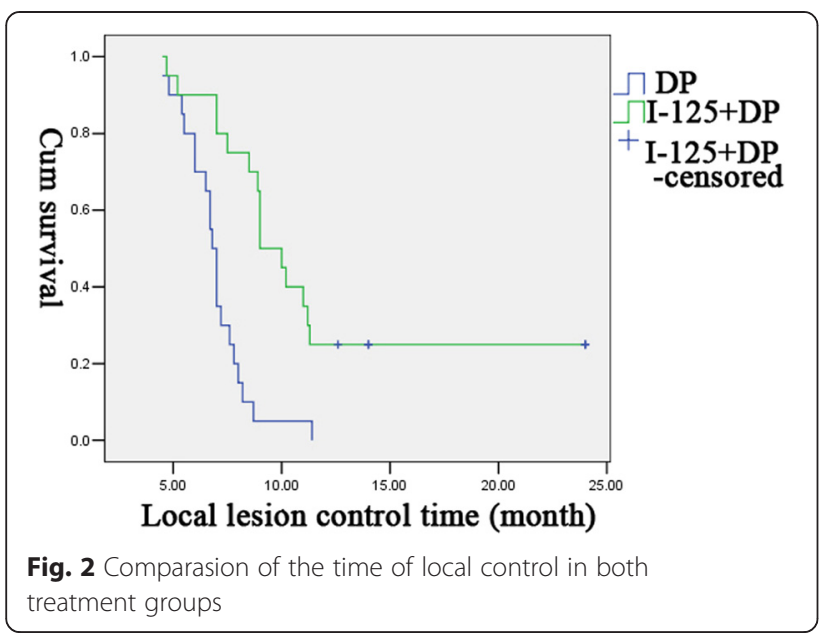

advanced NSCLC, which can provide a 2-year survival rate of $39.7 \%$, a median OS of up to 22 months, and a median PFS of 17 months [11]. However, for the patients with locally recurrent stage III NSCLC (stage IIIA and III B) after concurrent chemoradiotherapy, the treatment mainly depends on second-line chemotherapy or molecular targeted therapy, which can provide a median OS of 11.7-12.2 months, a median PFS of 2-3 months, and a one-year survival rate of $30 \%$ [12]. However, these therapies are not yet considered as the standard treatment for locally recurrent stage III NSCLC after concurrent chemoradiotherapy, further investigations are required to explore and optimize possible treatment regimens.

Development of computerized three-dimensional TPS has attracted more attention of physicians on CT-guide brachytherapy with radioactive seeds for treating malignant tumors [13]. The ${ }^{125}$ I radioactive seeds have an effective emission range of $1.7 \mathrm{~cm}$ in tissue. During the half-life of ${ }^{125}$ I radioactive seeds (59.6 days), tumor cells at different phases of the cell cycle can be destroyed by the gamma-rays emitted from the radioactive seed.

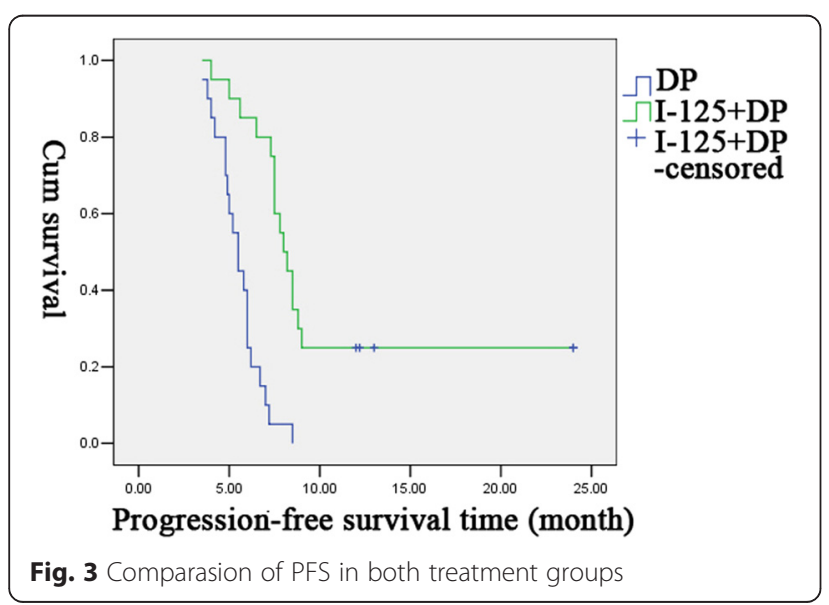

Previous studies have shown that the low radiation dose rate could increase the sensitivity of hypoxic tumor cells to radioactive rays and produce radiation-induced bystander effect to kill tumor cells [7, 14]. In vitro studies have shown that ${ }^{125} \mathrm{I}$ radioactive seeds up-regulated apoptosis-related genes, and regulated cell cycle and apoptosis of tumor cells [15]. Taken together, ${ }^{125}$ I radioactive seeds have the advantages including high conformality index and producing high dose in target volumes and low radioactive exposure to surrounding normal tissues, thus having great potential in the treatment of locally recurrent tumors [16].

Currently, brachytherapy with ${ }^{125}$ I seeds are widely used in clinic for the treatment of recurrent and metastatic prostate tumor and head and neck tumors [17-19]. However, this therapy has been rarely reported for treating patients with locally recurrent NSCLC. In this study we investigated the clinical efficacy of the combination of ${ }^{125} \mathrm{I}$ brachytherapy and chemotherapy in the patients with locally recurrent stage III NSCLC after concurrent chemoradiotherapy. Our results demonstrated that this combined therapy achieved satisfactory efficacy compared with chemotherapy alone. For the combined therapy, the median time of local control was 10 months. Three patients achieved progression free of disease after 24-month follow-up. The median PFS was 8 months. Three months after ${ }^{125}$ I brachytherapy, ORR was $69.2 \%(18 / 26)$. The rates of CR and PR were $38.5 \%(10 / 26)$ and $30.8 \%(8 / 26)$, respectively, which were significantly higher than those in the control group. Recent studies have indicated that local disease control rate is an important independent prognostic factor for the OS of patients with locally advanced lung cancer [20]. In the present study, ${ }^{125}$ I radioactive seeds were shown to have a good local tumor control. For three patients with well differentiated adenocarcinoma (tumor diameter $<3 \mathrm{~cm}$ with single metastatic lesion), the time of local control was longer than two years, suggesting that the degree of tumor differentiation, growth rate, and tumor size could affect the local efficacy in NSCLC patients.

Furthermiore, there was no occurrence of severe complications during the study, indicating that combined therapy of ${ }^{125}$ I brachytherapy and DP regimen is effective and safe for the treatment of locally recurrent stage III NSCLC after concurrent chemoradiotherapy. Further large-sale studies are needed to verify the potential of the combination of ${ }^{125} \mathrm{I}$ brachytherapy and second-line chemotherapy for treament of locally recurrent stage III NSCLC.

\section{Conclusions}

The combination of ${ }^{125}$ I brachytherapy and second-line chemotherapy is superior to chemotherapy alone and is an effective and safe therapy for this disease. 


\section{Competing interests}

The authors declare that they have no competing interests.

\section{Authors' contributions}

$X Y$ and $J L$ performed the study. $X L$ performed statistical analysis. $J H$ conceived the study. All authors read and approved the final manuscript.

\section{Acknowledgements}

We thank the patients enrolled in this study.

Received: 10 July 2015 Accepted: 27 September 2015

Published online: 06 October 2015

\section{References}

1. Wagner TD, Yang GY. The role of chemotherapy and radiation in the treatment of locally advanced non-small cell lung cancer (NSCLC). Curr Drug Targets. 2010;11:67-73.

2. Ramlau R, Gorbunova V, Ciuleanu TE, Novello S, Ozguroglu M, Goksel T, et al. Aflibercept and Docetaxel versus Docetaxel alone after platinum failure in patients with advanced or metastatic non-small-cell lung cancer: a randomized, controlled phase III trial. J Clin Oncol. 2012;30:3640-7.

3. Lerouge D, Rivière A, Dansin E, Chouaid C, Dujon C, Schott R, et al. A phase II study of cisplatin with intravenous and oral vinorelbine as induction chemotherapy followed by concomitant chemoradiotherapy with oral vinorelbine and cisplatin for locally advanced non-small cell lung cancer BMC Cancer. 2014;14:231.

4. Kim M, Lee J, Ha B, Lee R, Lee KJ, Suh HS. Factors predicting radiation pneumonitis in locally advanced non-small cell lung cancer. Radiat Oncol J. 2011:29:181-90.

5. Fleischman EH, Kagan AR, Streeter OE, Tyrell J, Wollin M, Leagre CA, et al. lodine125 interstitial brachytherapy in the treatment of carcinoma of the lung. J Surg Oncol. 1992;49:25-8.

6. Wang ZM, Lu J, Liu T, Chen KM, Huang G, Liu FJ. CT-guided interstitial brachytherapy of inoperable non-small cell lung cancer. Lung Cancer. 2011;74:253-7.

7. Chen HH, Jia RF, Yu L, Zhao MJ, Shao CL, Cheng WY. Bystander effects induced by continuous

low-dose-rate 125 seeds potentiate the killing action of irradiation on human lung cancer cells in vitro. Int J Radiat Oncol Biol Phys. 2008;172:1560-6.

8. Martínez-Monge R, Pagola M, Vivas I, López-Picazo JM. CT-guided permanent brachytherapy for patients with medically inoperable early-stage non-small cell lung cancer (NSCLC). Lung Cancer. 2008;61:209-13.

9. Fernando HC, Landreneau RJ, Mandrekar SJ, Nichols FC, Hillman SL, Heron $\mathrm{DE}$, et al. Impact of brachytherapy on local recurrence rates after sublobar resection: results from ACOSOG Z4032 (Alliance), a phase III randomized trial for high-risk operable non-small-cell lung cancer. J Clin Oncol. 2014;32:2456-62

10. Cox JD, Stenz J, Pajak TF. Toxicity criteria of the radiation therapy oncology group (RTOG) and the European organization for research and treatment of cancer. Int J Radiat Oncol Biol Phys. 1995;31:1341-6.

11. Crvenkova S, Krstevska V. Sequential chemoradiotherapy compared with concurrent chemoradiotherapy in locally advanced non-small cell lung cancer: our experience. Prilozi. 2009;30:197-207.

12. Sun $Y$, Wu YL, Zhou CC, Zhang L, Zhang L, Liu XY et al. Second-line pemetrexed versus docetaxel in Chinese patients with locally advanced or metastatic non-small cell lung cancer: A randomized, open-label study. Lung Cancer. 2013;79:143-50.

13. Huckle A, Al-Qaisieh B, Bownes P. Methods of verifying the output of the treatment planning system used for high dose rate (HDR) prostate brachytherapy. Radiother Oncol. 2012;103:261-5.

14. Guckenberger M, Kavanagh A, Partridge M. Combining advanced radiotherapy technologies to maximize safety and tumor control probability in stage III non-small cell lung cancer. Strahlenther Onkol. 2012;188:894-900.

15. Chen H, Bao Y, Yu L, Jia R, Cheng W, Shao C. Comparison of cellular damage response to

low-dose-rate 125 I seed irradiation and high-dose-rate gamma irradiation in human lung cancer cells. Brachytherapy. 2012;11:149-56.

16. Suchorska B, Ruge M, Treuer H, Sturm V, Voges J. Stereotactic brachytherapy of low-grade cerebral glioma after tumor resection. Neuro Oncol. 2011;13:1133-42

17. Zilli T, Boudreau C, Filion EJ, Donath D, Taussky D. Combined intensitymodulated radiation therapy vs. three-dimensional highly conformal radiotherapy after (125)l prostate permanent seed brachytherapy: a comparative treatment planning study. Brachytherapy. 2011;10:416-20.

18. Tran AT, Mandall P, Swindell R, Hoskin PJ, Bottomley DM, Logue JP, et al. Biochemical outcomes for patients with intermediate risk prostate cancer treated with 1-125 interstitial brachytherapy monotherapy. Radiother Oncol. 2013;109:235-40.

19. Zhu L, Jiang Y, Wang J, Ran W, Yuan H, Liu C, et al. An investigation of 1251 seed permanent implantation for recurrent carcinoma in the head and neck after surgery and external beam radiotherapy. World J Surg Oncol. 2013;11:60.

20. Machtay M, Paulus R, Moughan J, Komaki R, Bradley JE, Choy H, et al. Defining local-regional control and its importance in locally advanced nonsmall cell lung carcinoma. J Thorac Oncol. 2012;7:716-22.

\section{Submit your next manuscript to BioMed Central and take full advantage of:}

- Convenient online submission

- Thorough peer review

- No space constraints or color figure charges

- Immediate publication on acceptance

- Inclusion in PubMed, CAS, Scopus and Google Scholar

- Research which is freely available for redistribution 